\title{
Lyon bracing in adolescent females with idiopathic scoliosis: assessment of results according to the SRS committee on bracing and nonoperative management standardization criteria
}

\author{
AG Aulisa ${ }^{1 *}$, V Guzzanti ${ }^{1}$, P Perisano ${ }^{2}$, G Scudieri ${ }^{2}$, L Bocchino ${ }^{2}$, S Teramo ${ }^{2}$, L Aulisa ${ }^{2}$ \\ From 9th International Conference on Conservative Management of Spinal Deformities - SOSORT 2012 \\ Annual Meeting \\ Milan, Italy. 10-12 May 2012
}

\section{Background}

The Lyon brace, devised by Stagnara in 1950, is commonly prescribed in many European countries, and is based on the three-point pressure system. The Lyon brace also applies derotational forces to the spine, with the main thoracic plate pushing the hump from the posterior convexity toward the anterior concavity of the scoliotic curve. Lyon bracing is considered to be an effective means for conservative treatment of scoliosis.

\section{Aim}

The purpose of the present study was to evaluate the efficacy of Lyon bracing in the correction of thoracic curves, in agreement with the Scoliosis Research Society (SRS) Committee on Bracing and Nonoperative Management Standardisation Criteria.

\section{Methods}

Sixty-eight adolescent females (mean age $11.8 \pm 0.5$ years) with a thoracic curve and a pre-treatment Risser score ranging from 0 to 2 were enrolled. All patients were prescribed with full-time Lyon bracing. The minimum duration of follow-up was 24 months (mean: $36.4 \pm 27.0$ months). Antero-posterior radiographs were used to estimate the curve magnitude (CM) at 5 time points: beginning of treatment ( $\mathrm{t} 1)$, one year after the beginning of treatment ( $\mathrm{t} 2)$, intermediate time between $\mathrm{t} 1$ and $\mathrm{t} 4 \mathrm{(t} 3)$, end of weaning (t4), 2-year minimum follow-up from $t 4$ (t5). Three situations were distinguished: curve correction, curve stabilization and curve progression.

\section{Results}

$\mathrm{CM}$ mean value was $34.1 \pm 7.4 \mathrm{SD}$ at $\mathrm{t} 1$ and $23.1 \pm 10.4$ $\mathrm{SD}$ at $\mathrm{t} 5$. Curve correction was accomplished in $83.8 \%$ of patients, whereas a curve stabilisation was obtained in $16.2 \%$ of patients. None of the patients experienced a curve progression.

\section{Conclusion}

The Lyon brace, due to its biomechanical action on vertebral modelling, is highly effective in correcting thoracic curves.

\section{Author details}

${ }^{1}$ Orthopaedic Department, Children's Hospital Bambino Gesù, Rome, Italy. 2Department of Orthopaedics, University Hospital "Agostino Gemelli", Catholic University of the Sacred Heart, Rome, Italy.

Published: 3 June 2013

\section{References}

1. de Mauroy JC, Lecante C, Barral F, Daureu D, Gualerzi S, Gagliano R: The Lyon brace. Disabil Rehabil Assist Technol 2008, 3(3):139-145.

2. de Mauroy JC, Lecante C, Barral F: "Brace Technology" Thematic Series The Lyon approach to the conservative treatment of scoliosis. Scoliosis 2011, 6(1):4

3. Richards BS, Bernstein RM, D'Amato CR, Thompson GH: Standardization of criteria for adolescent idiopathic scoliosis brace studies: SRS Committee on Bracing and Nonoperative Management. Spine 2005, 30(18):2068-2075, discussion 2076-2067.

doi:10.1186/1748-7161-8-S1-033

Cite this article as: Aulisa et al:: Lyon bracing in adolescent females with idiopathic scoliosis: assessment of results according to the SRS committee on bracing and nonoperative management standardization criteria. Scoliosis 2013 8(Suppl 1):033

${ }^{1}$ Orthopaedic Department, Children's Hospital Bambino Gesù, Rome, Italy Full list of author information is available at the end of the article

(c) 2013 Aulisa et al; licensee BioMed Central Ltd. This is an Open Access article distributed under the terms of the Creative Commons 